\title{
High stakes and high emotions: providing safe care in Canadian emergency departments
}

This article was published in the following Dove Press journal:

Open Access Emergency Medicine

19 January 2017

Number of times this article has been viewed

\author{
Samina $A i^{1,2}$ \\ Denise Thomson ${ }^{3}$ \\ Timothy A D Graham ${ }^{4}$ \\ Sean E Rickard ${ }^{3}$ \\ Antonia S Stang ${ }^{5}$ \\ 'Women and Children's Health \\ Research Institute, ${ }^{2}$ Department of \\ Pediatrics, ${ }^{3}$ Cochrane Child Health \\ Field, Department of Pediatrics, \\ University of Alberta, Edmonton, \\ ${ }^{4}$ Department of Emergency Medicine, \\ ${ }^{5}$ Section of Emergency Medicine, \\ Department of Pediatrics, University \\ of Calgary, Calgary, AB, Canada
}

Background: The high-paced, unpredictable environment of the emergency department (ED) contributes to errors in patient safety. The ED setting becomes even more challenging when dealing with critically ill patients, particularly with children, where variations in size, weight, and form present practical difficulties in many aspects of care. In this commentary, we will explore the impact of the health care providers' emotional reactions while caring for critically ill patients, and how this can be interpreted and addressed as a patient safety issue.

Discussion: ED health care providers encounter high-stakes, high-stress clinical scenarios, such as pediatric cardiac arrest or resuscitation. This health care providers' stress, and at times, distress, and its potential contribution to medical error, is underrepresented in the current medical literature. Most patient safety research is limited to error reporting systems, especially medication-related ones, an approach that ignores the effects of health care provider stress as a source of error, and limits our ability to learn from the event. Ways to mitigate this stress and avoid this type of patient safety concern might include simulation training for rare, high-acuity events, use of pre-determined clinical order sets, and post-event debriefing.

Conclusion: While there are physiologic and anatomic differences that contribute to patient safety, we believe that they are insufficient to explain the need to address critical life-threatening event-related patient safety issues for both adults and, especially, children. Many factors make patient safety during critical medical events distinct from general patient safety issues, but it is, perhaps, this heightened high-stress, emotional climate that is the most distinct and important part of all. We believe that consideration of this concept is essential when discussing safety improvement in critical medical events.

Keywords: emergency department, pediatrics, patient safety, distress

\section{Background}

High-stakes health conditions and their attendant care scenarios can lead to enhanced stress for all emergency department (ED) health care providers. Examples of such scenarios can include the care of critically ill children, cardiac arrest resuscitation, and dealing with family member death notification. ${ }^{1-4}$ Critically ill children, in particular, seem to engender a strong emotional reaction; when children are sick or injured, the medical staff need to care not only for the child, but also the family. ${ }^{5}$

The high-paced, unpredictable environment of the ED can lead to increased general concerns regarding patient safety, and specifically, cognitive errors of omission and commission..$^{6-8}$ In fact, the ED has been described as a "natural laboratory for the study of error". ${ }^{9}$ The unpredictable nature of the ED becomes even more challenging when dealing with the critically ill patient, particularly with children, where variations in
Correspondence: Samina Ali

Department of Pediatrics, Edmonton

Clinic Health Academy, I I405-87

Avenue, Edmonton, AB T6G IC9,

Canada

Tel +I 7802485574

Fax +I 8887758876

Email sali@ualberta.ca 
size, weight, and form present practical difficulties for many aspects of care, including neuro-developmental assessment, intravenous access, and medication dosing. ${ }^{10,11}$ This layers even more decision density to an already emotionally charged situation, ${ }^{12}$ and the resulting high stress situation may affect critical decision making. In this commentary, we will explore the impact of health care providers' emotional reactions while caring for critically ill patients, and how this can be interpreted and addressed as a patient safety issue.

\section{Hypothetical case for discussion}

Jane is a healthy two-year-old girl. She is brought by her parents after they witnessed multiple brief seizures at home. The convulsing recurs in the car, and she is actively seizing when she arrives in the ED. She looks ashen and cyanotic and has critically abnormal vital signs. Of the three nurses on duty, only one has previous pediatric experience. Jane's parents and sister arrive with her; the mother is wailing, the sister is white-faced and tense, and the father is pacing and frantically asking the care team to "do something, anything to save my little girl". During the resuscitation, there is delay and some confusion relating to the appropriate dose of benzodiazepine, and in the process of leaving the room to check and get the medications prepared, two nurses give the same dose independently, resulting in respiratory failure, and the need for urgent intubation.

It would be expected that such a clinical scenario would induce stress in the health care providers involved. This health care provider stress, and, at times, distress, and its potential contribution to medical error, is underrepresented in the current medical literature. A large proportion of emergency care in Canada is delivered in community based EDs. Health care providers working in these EDs may infrequently encounter critically ill patients and rarely treat children with severe, life threatening pediatric emergencies. ${ }^{13}$ These high-stakes situations, their potential rarity, and the requirement for highly protocolized care was one of the reasons that initiatives such as the Advanced Trauma Life Support and Pediatric Advanced Life Support programs were developed. These programs advocate for a series of consistent steps that decrease the decision density during these stressful medical events. ${ }^{14,15}$

Health care providers' emotional response to a patient may also influence medical decision-making in high-stakes scenarios, a type of cognitive decision making bias Croskerry has termed "visceral bias". ${ }^{12}$ He states "when our viscera are aroused we do not make good decisions", and suggests that health care providers need to monitor their affective state as a matter of professional responsibility. Croskerry warns that health care providers' emotional reactions to a patient can lead to adverse clinical outcomes. We contend that the caregiver's emotional state in high-stress care situations is, in and of itself, likely contributing to error, and that this is rarely addressed in health care provider training. In a medical error and stress study of the attitudes of nurses, residents, and attending physicians, $70 \%$ of all medical respondents agreed that "my decision making ability is as good in medical emergencies as in routine situations". ${ }^{16}$ In general, only a minority of respondents openly recognized the effects of stress on performance, despite its effects on performance being well-recognized in both the aviation and medical world. ${ }^{16}$ Put another way, there is a disconnect between health care providers' perceived ability to provide consistent care, and the greater rates of error seen in higher stress situations compared to those that are less emergent. ${ }^{17}$

Most patient safety research is limited to error reporting systems, especially medication-related ones. In our hypothetical case, it would be quite possible to label the double-dosing of the benzodiazepine as a simple medication dosing error, but this would be ignoring the effects of health care provider stress as a source of error that could be mitigated. This approach limits our capacity to fully learn from this event. Recognizing the role of emotions and stress on clinical decision making and performance may lead to the consideration of other relevant mitigating strategies. Examples of such strategies might include limits on shift duration, consideration of shift timing and team composition, and basic awareness training for providers on the impact of emotion on information processing. ${ }^{17,18}$

The overarching context of our hypothetical case is the high-stakes, emotionally stressful climate of emergency care. This is further exemplified in the emergency treatment of children, in particular. This high-stakes, emotionally stressful climate is comprised of the responsibility for sick or injured children felt by both parents and professionals; the knowledge that acute care given to children can affect their lives for decades to come (ie, 'life lost'); and the fact that children are often accompanied to the ED by family members who may, themselves, be experiencing significant anxiety and distress. In child health care, "the parents are entrusting the doctor with the wellbeing of their most cherished and precious possession". ${ }^{5}$ An indelible characteristic of providing health care to children is the inherent trust placed in those who deliver it.

There are some possible ways to mitigate the clinicians' high stress in these cases. Two Canadian studies have shown that the use of a preprinted, dedicated order sheet is associated with a decrease in the risk of error in critical care 
provision. ${ }^{19,20}$ Secondly, there is a role for simulation-based education and outreach to help prepare providers for high acuity, relatively infrequent events. ${ }^{21,22}$ Simulation likely plays an important role in such training, not only for the acquisition of medical skills and knowledge, but also for learning teamwork and communication strategies that may help prevent errors from occurring. Finally, this case raises the importance of debriefing after such incidents, as this type of critical incident can have lasting effects on the health care team members. ${ }^{23,24}$

\section{Conclusion}

The general patient safety literature already includes analysis of factors such as patient size variation, pediatric differences from adult anatomy, and potential complications involving both equipment size and administration of medications. Conjoined with these variables is the specificity of clinical knowledge required to address them routinely. These are the physiologic and anatomic differences that contribute to patient safety; however, we believe that they are insufficient to explain the need to address critical life-threatening eventrelated patient safety for both adults and, especially, children. Many factors make patient safety during critical medical events distinct from general patient safety issues, but it is, perhaps, this heightened high-stress, emotional climate that is the most distinct and important. We believe that consideration of this concept is essential when discussing safety improvement in critical medical events. Further qualitative research to understand the impact of emotions and stress on medical decision making, and the testing of preventative interventions such as clinical decision tools and simulation training are necessary steps in improving safe care in the acute care setting.

\section{Acknowledgments}

We acknowledge with thanks funding support from the Knowledge Translation Research Grant program of Alberta Innovates-Health Solutions, and the support for the Cochrane Child Health Field of the Canadian Institutes of Health Research (Knowledge Synthesis and Translation by Cochrane Canada, CON-105529).

\section{Disclosure}

The authors report no conflicts of interest in this work.

\section{References}

1. Hunziker S, Pagani S, Fasler K, Tschan F, Semmer NK, Marsch S. Impact of a stress coping strategy on perceived stress levels and performance during a simulated cardiopulmonary resuscitation: a randomized controlled trial. BMC Emerg Med. 2013;13:8.
2. Tye C. Qualified nurses' perceptions of the needs of suddenly bereaved family members in the accident and emergency department. JAdv Nurs. 1993;18(6):48-56.

3. Viswanathan R, Clark JJ, Viswanathan K. Physicians' and the public's attitudes on communication about death. Arch Intern Med. 1986; 146(10):2029-2033

4. Gilleland J, McGugan J, Brooks S, Dobbins M, Ploeg J. Caring for critically ill children in the community: a needs assessment. BMJ Qual Saf. 2014;23(6):490-498.

5. Everitt I, Jan A. Approach to the paediatric patient. In: Cameron P, Jelinek G, Everitt I, Browne G, Raftos J, editors. Textbook of paediatric emergency medicine. Churchill Livingstone: Edinburgh; 2006:3-13.

6. Croskerry P. The importance of cognitive errors in diagnosis and strategies to minimize them. Acad Med. 2003;78(8):775-780.

7. Committee on the future of emergency care in the United States health system. Emergency care for children: Growing pains. The National Academies Press: Washington, DC; 2007.

8. Barata IA, Benjamin LS, Mace SE, Herman MI, Goldman RD. Pediatric patient safety in the prehospital/emergency department setting. Pediatr Emerg Care. 2007;23(6):412-418.

9. Croskerry P, Sinclair D. Emergency medicine: a practice prone to error? CJEM. 2001;3(4):271-276.

10. Feleke R, Kalynych CL, Lundblom B, Wears R, Luten R, Kling D. Color coded medication safety system reduces community pediatric emergency nursing medication errors. J Patient Saf. 2009;5(2):79-85.

11. Woods DM, Holl JL, Shonkoff JP, Mehra M, Ogata ES, Weiss KB. Childspecific risk factors and patient safety. J Patient Saf. 2005;1(1):17-22.

12. Croskerry P. Achieving quality in clinical decision making: Cognitive strategies and detection of bias. Acad Emerg Med. 2002;9(11):1184-1204

13. American Academy of Pediatrics Committee on Pediatric Emergency Medicine, American College of Emergency Physicians, Pediatric Committee, Emergency Nurses Association, Pediatric Committee. Joint policy statement--guidelines for care of children in the emergency department. Ann Emerg Med. 2009;54(4):543-52.

14. Styner R. The light of the moon: life, death and the birth of advanced trauma life support. Lulu Publishing; 2012.

15. Cheng A, Rodgers DL, van der Jagt É, Eppich W, O'Donnell J. Evolution of the pediatric advanced life support course: enhanced learning with a new debriefing tool and web-based module for pediatric advanced life support instructors. Pediatr Crit Care Med. 2012;13(5):589-595.

16. Sexton JB, Thomas EJ, Helmreich RL. Error, stress, and teamwork in medicine and aviation: cross sectional surveys. BMJ. 2000;320(7237): 745-749.

17. LeBlanc VR. The effects of acute stress on performance: implications for health professions education. Acad Med. 2009;84(10 Suppl):S25-33.

18. Resnick ML. The effect of affect: decision making in the emotional context of health care. 2012 Symposium on Human Factors and Ergonomics in Health Care. Available from: http://www.hfes.org/web/ HFESMeetings/HCS2012/Resnick-ProviderSafety-poster-1.19.pdf. Accessed on December 1, 2016.

19. Kozer E, Scolnik D, Macpherson A, Rauchwerger D, Koren G. Using a preprinted order sheet to reduce prescription errors in a pediatric emergency department: a randomized, controlled trial. Pediatrics. 2005;116(6):1299-1302.

20. Larose G, Bailey B, Lebel D. Quality of orders for medication in the resuscitation room of a pediatric emergency department. Pediatr Emerg Care. 2008;24(9):609-614.

21. Kessler D, Walsh B, Whitfill T, Gangadharan S, Gawel M, Brown L, Auerbach M. Disparities in adherence to pediatric sepsis guidelines across a spectrum of emergency departments: a multicenter, crosssectional observational in situ simulation study. J Emerg Med. 2016; 50(3):403-415.e1-3.

22. Lin $Y$, Cheng A. The role of simulation in teaching pediatric resuscitation: current perspectives. Adv Med Educ Pract. 2015;6:239-248.

23. Aggarwal R, Mytton OT, Derbrew M, et al. Training and simulation for patient safety. Qual Saf Health Care. 2010;19 Suppl 2:i34-43.

24. Vaithilingam N, Jain S, Davies D. Helping the helpers: debriefing following an adverse incident. The Obstetrician and Gynaecologist. 2008;10:251-256. 


\section{Publish your work in this journal}

The Open Access Emergency Medicine is an international, peerreviewed, open access journal publishing original research, reports, editorials, reviews and commentaries on all aspects of emergency medicine. The manuscript management system is completely online and includes a very quick and fair peer-review system, which is all

Submit your manuscript here: https://www.dovepress.com/open-access-emergency-medicine-journal

easy to use. Visit http://www.dovepress.com/testimonials.php to read real quotes from published authors. 